\title{
OPEN A meta-analysis of accuracy and sensitivity of chest $C T$ and RT-PCR in COVID-19 diagnosis
}

\author{
Fatemeh Khatami ${ }^{1}$, Mohammad Saatchi ${ }^{2}$, Seyed Saeed Tamehri Zadeh ${ }^{1}$, \\ Zahra Sadat Aghamir ${ }^{3}$, Alireza Namazi Shabestari ${ }^{4}$, Leonardo Oliveira Reis ${ }^{5}$ \& \\ Seyed Mohammad Kazem Aghamir ${ }^{1 凶}$
}

Nowadays there is an ongoing acute respiratory outbreak caused by the novel highly contagious coronavirus (COVID-19). The diagnostic protocol is based on quantitative reverse-transcription polymerase chain reaction (RT-PCR) and chests CT scan, with uncertain accuracy. This meta-analysis study determines the diagnostic value of an initial chest CT scan in patients with COVID-19 infection in comparison with RT-PCR. Three main databases; PubMed (MEDLINE), Scopus, and EMBASE were systematically searched for all published literature from January 1st, 2019, to the 21st May 2020 with the keywords "COVID19 virus", "2019 novel coronavirus", "Wuhan coronavirus", "2019nCoV", "X-Ray Computed Tomography", "Polymerase Chain Reaction", "Reverse Transcriptase PCR", and "PCR Reverse Transcriptase". All relevant case-series, cross-sectional, and cohort studies were selected. Data extraction and analysis were performed using STATA v.14.0SE (College Station, TX, USA) and RevMan 5. Among 1022 articles, 60 studies were eligible for totalizing 5744 patients. The overall sensitivity, specificity, positive predictive value, and negative predictive value of chest CT scan compared to RT-PCR were $87 \%$ (95\% Cl 85-90\%), 46\% (95\% Cl 29-63\%), 69\% (95\% Cl 56-72\%), and $89 \%$ (95\% Cl 82-96\%), respectively. It is important to rely on the repeated RT-PCR three times to give $99 \%$ accuracy, especially in negative samples. Regarding the overall diagnostic sensitivity of $87 \%$ for chest CT, the RT-PCR testing is essential and should be repeated to escape misdiagnosis.

In late December of 2019, a cluster of patients was diagnosed with a strange viral pneumonia in Wuhan City, Hubei Province, China, which later was confirmed to be caused by the novel coronavirus (the disease named COVID-19) ${ }^{1}$. Up to now, millions of cases have been identified, causing thousands of deaths at an alarming pace worldwide. Officially, the World Health Organization has declared the pandemic of COVID-19² and due to the non-existence of effective antiviral drug or vaccine, both detecting patient at an early stage and immediate patient isolation play a mandatory role in the fighting against COVID- $19^{3}$.

The chest computed tomography (CT) scan plays a central role on the disease staging and checking the treatment efficacy, while the reverse transcription-polymerase chain reaction (RT-PCR) remains the mainstay of COVID-19 diagnosis ${ }^{4,5}$, though limited to identify the virus, which poses important restrictions ${ }^{6}$.

Recent studies claim that initial chest CT may enable the detection of the disease with higher sensitivity in comparison to RT-PCR ${ }^{7}$. This systematic review and meta-analysis were performed to determine the diagnostic accuracy of the initial chest CT scan compared to RT-PCR in COVID-19 patients.

\section{Materials and methods}

All stages of this study followed the PRISMA guidelines and all relevant English, Chinese, and other language case-series, cross-sectional, and cohort studies were selected and checked for scientific validity.

Inclusion criteria: observational epidemiological study design, clear report of the number of positive cases by PCR and chest CT, and the ability to calculate accuracy indicators.

Exclusion criteria: case reports or not meeting one or more inclusion criteria.

\footnotetext{
${ }^{1}$ Urology Research Center, Tehran University of Medical Sciences, Tehran, Iran. ${ }^{2}$ Department of Epidemiology and Biostatistics, School of Public Health, Tehran University of Medical Sciences, Tehran, Iran. ${ }^{3}$ Faculty of Dentistry, Tehran University of Medical Sciences, Tehran, Iran. ${ }^{4}$ Department of Geriatric Medicine, School of Medicine, Tehran University of Medical Sciences, Tehran, Iran. ${ }^{5}$ UroScience and Department of Surgery (Urology), School of Medical Sciences, University of Campinas, Unicamp, and Pontifical Catholic University of Campinas, PUC-Campinas, Campinas, São Paulo, Brazil. ${ }^{\varpi}$ email: mkaghamir@tums.ac.ir
} 
Search strategy. All relevant literature from three main databases: MEDLINE (PubMed), Scopus, and EMBASE were explored from January 1st, 2019, to the 21th May 2020, using the keywords "COVID19 virus", "2019 novel coronavirus", "Wuhan coronavirus", "2019-nCoV", "X-Ray Computed Tomography", "Polymerase Chain Reaction", "Reverse Transcriptase PCR", and "PCR Reverse Transcriptase” (Supplementary file 1). The references of the selected articles were also reviewed.

The variables extracted included the first author name, publication year, country and city of the study, subjects average age, gender, study design, total sample size, true positives, true negatives, false positives, and false negatives.

Data extraction and statistical analysis. Two researchers (SZA and SSTZ) screened articles separately by checking titles and abstracts. Disagreements were solved by a third one (FKH). Included articles had data of confirmed COVID-19 patients by chest CT scan and quantitative real-time polymerase chain reaction (RT-PCR) and were accessed in full text. The quality assessment was performed by the Newcastle-Ottawa Scale (NOS) assessment tool. The papers that receive scores more than 6 were reflected as the "high quality" and underwent additional meta-analysis steps.

The outcomes of interest, including the CT-scan to identify COVID-19 were submitted to summary receiver operating characteristic (SROC) curve by the random effect model for sensitivity and specificity.

Sensitivity, indicating the capacity of index test to identify patients, considered by "Sensitivity $=\mathrm{TP} /(\mathrm{TP}+\mathrm{FN})$ ". Specificity as the examination to remove disease-free, calculated by "Specificity $=\mathrm{TN} /(\mathrm{FP}+\mathrm{TN})$ ". The Metaprop command to calculate sensitivity and specificity excluded studies that have reported $100 \%$ sensitivity or specificity.

Positive Predictive Value (PPV) is the probability of disease if the test is positive calculated by "Positive predictive Value $=\mathrm{TP} /(\mathrm{FP}+\mathrm{TP}) "$. Negative Predictive Value $(\mathrm{NPV})$ is the probability of disease-free if the test is negative calculated by "negative predictive value $=\mathrm{TN} /(\mathrm{FN}+\mathrm{TN}) "$.

The Cochran's Q-test of heterogeneity at $5 \%$ was used to evaluate statistical heterogeneity based on the Higgins classification in which an $\mathrm{I}^{2}>75 \%$ means significant heterogeneity.

Deeks' funnel plot was used to evaluate publication bias by the "Metafunnel". Briefly, to create the funnel plot, the odds ratio were first calculated using the equations of (TP/FN)/(FP/TN) and after estimating the odds ratio logarithm, the standard error of odds ratio was calculated. Extracted data were collected in Excel 2007 (Microsoft Corporation, Redmond, CA) and analysis was done by using STATA v.14.0SE (College Station, TX, USA) and RevMan 5.

\section{Results}

Among 1022 identified articles, 115 were considered eligible and after the NOS screening, 60 articles, including 5744 subjects were included, all published in the first quarter of 2020 (Fig. 1).

A summary of the information of included articles is shown in Table 1. The forest plot, False Positives (FP), False Negatives (FN), True Positives (TP), True Negatives (TN), Sensitivity, Specificity, and 95\% Confidence Intervals (CI) of each study are shown in Fig. 2 .

Sensitivity ranged from 25 to $100 \%$ and the specificity was estimated to vary from 19 to $70 \%$.

After excluding studies reporting $100 \%$ sensitivity or specificity, the sensitivity was ranging from 25 to $97 \%$ and specificity from 25 to $70 \%$ (Figs. 3, 4). Based on 37 studies, the sensitivity of CT compared to PCR was $87 \%$ (95\% CI 85-90\%) and based on seven studies the specificity of CT was $46 \%$ (95\% CI 29-63\%).

The positive predictive value of CT was $69 \%$ (95\% CI 56-72\%) and the negative predictive value was $89 \%$ (95\% CI 82-96\%) and the variation of the estimated numbers were $33 \%$ to $97 \%$ and $33 \%$ to $96 \%$ for PPV and NPV, respectively (Figs. 5, 6).

The symmetry between the two sides of the funnel plot regression line indicates that the included publications are not biased. However, due to a large number of zeros in the FP and TN cells, it was possible to calculate the odds ratio for six studies only, and the interpretation of this plot in our study should be done with caution (Fig. 7).

Table 2 includes 35 studies with the first RT-PCR test of the suspected patients available (subsequent RT-PCR data were included if available). Moreover, the swabs should have been taken from sputum, nasopharyngeal, oropharyngeal, nose, or throat and if a combination was used, nasopharyngeal or throat swab was considered as the primary.

The COVID-19 diagnosis was confirmed by positive result of the first, second, third, and fourth RT-PCR tests and also information of patients who had negative results until the fourth test or no more than one test conducted, but considered as confirmed or most likely ill later according to more RT-PCR tests or examining other swabs, clinical manifestations, typical chest CT scan's features or developmental changes in the series of CT scans or a mixture of prior methods.

In the articles with more than 10 total confirmed patients (first 10 articles included), the RT-PCR test could diagnose $58.9 \%$ of the COVID-19 infected patients in the first test, and about $41.1 \%$ of infected patients could not be recognized in the first place by RT-PCR test. Among these 10 articles, 5 included the information of second tests (number 1, 2, 3, 7 and 9). In these five articles, the mean percentage of secondary diagnosed patients divided by total confirmed patients is $18.6 \%$. Out of 4 articles (number 1,2,3 and 7) with the exact data of thirdly and fourthly conducted tests, the mean percentage of positivity are $6.3 \%$ and $0.7 \%$, respectively. Moreover, the percentage of patients who were not diagnosed after 4 times of repeating the test is $8.6 \%$ (in the previous 4 articles). The numbers and sequences of primers and probes could be influential on PCR sensitivity and specificity which were surveyed in Table 3. 

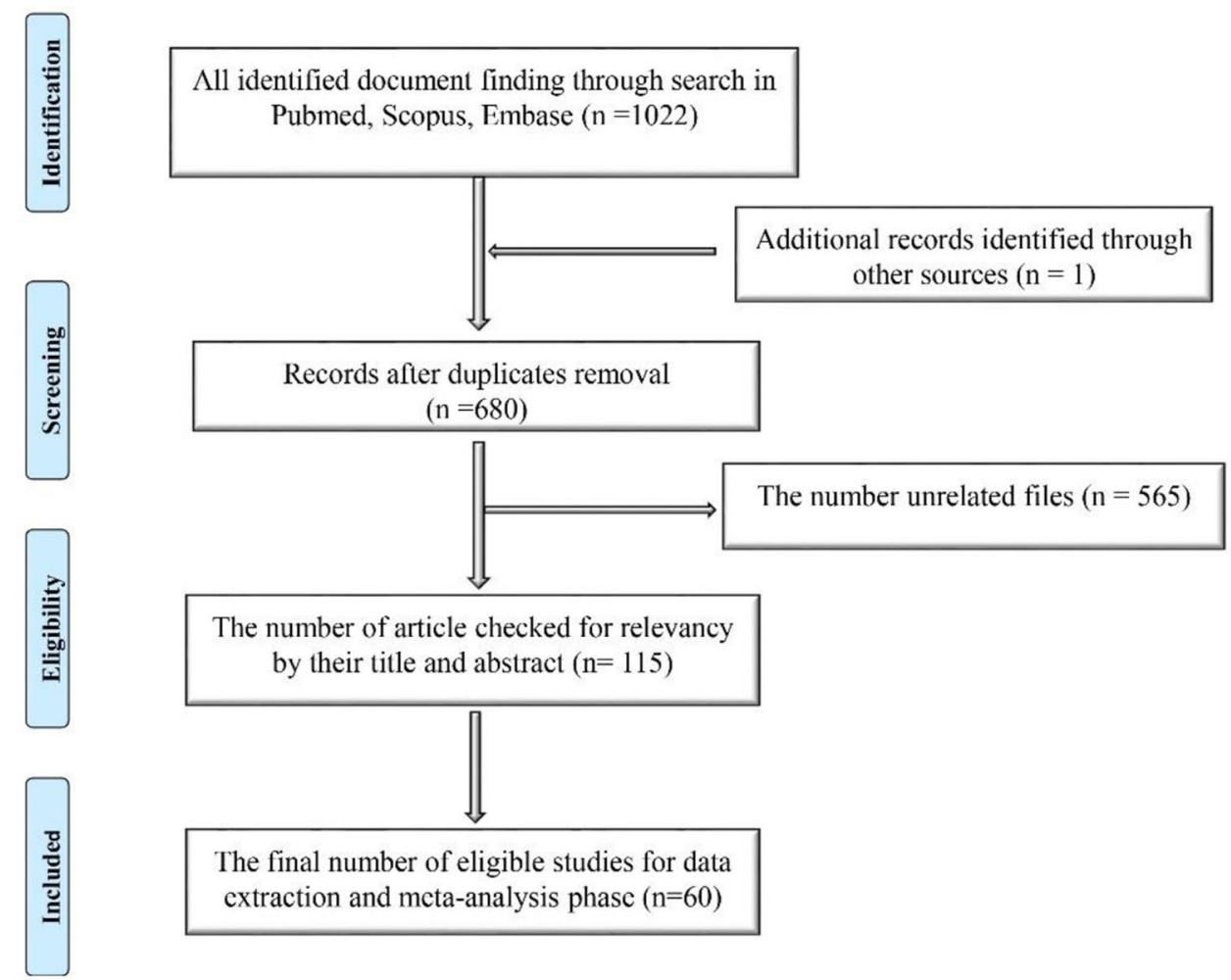

The number of article checked for relevancy by their title and abstract $(n=115)$

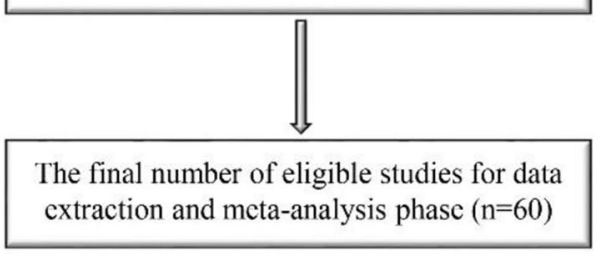

Figure 1. The number of articles during several steps based on the PRISMA flow diagram (2009). (http://www. prisma-statement.org/PRISMAStatement/CitingAndUsingPRISMA.aspx).

As we can see in Table 3, in the case report by Wendong $\mathrm{Hao}^{44}$, using one pair of primer and probe did not indicate a positive result at first but in the fourth repeated test. In another case report by Feng Ly ${ }^{65}$, the oropharyngeal swab by detection of $\mathrm{N}$ gene showed a positive result in the third, fourth, and fifth time, whereas ORF1ab detection showed a positive result in the fifth examination. On the other hand, Xavier Marchand-Senécal et al. ${ }^{67}$ and Yosuke Hirotsu et al. ${ }^{61}$ reported 2 cases that were diagnosed initially with one pair of primer and probe of PCR test.

By using 2 pairs of primer and probe, the mean of initially detecting patients divided by total confirmed patients is $51.3 \%$ in the 4 studies above. Also, Qing Chen $^{52}$ findings with the utilization of 3 pairs of primer and probe caused $100 \%$ of initially discovering COVID-19 patients ${ }^{52}$. Moreover, using 7 sets of primers and probes also resulted positively for the first test ${ }^{61}$. Based on limited data available, it seems that the greater the number of primer and probe, more likely to initially detect patients, although more specific information is needed from future studies.

\section{Discussion}

Considering the outcomes of RT-PCR as a reference, in our meta-analysis, the sensitivity and specificity of initial chest CT scan for detecting patients, who were highly suspicious for COVID-19, were $87 \%$ and $43 \%$ respectively. The PPV and NPV of CT scans were $67 \%$ and $84 \%$ respectively.

It means that $67 \%$ of individuals with positive chest CT scans had positive RT-PCR and $84 \%$ of individuals with negative chest CT scans had negative RT-PCR. So, a chest CT scan may have beneficial diagnostic features as adjuvant diagnostic tool compared to RT-PCR ${ }^{36,68}$.

Tao Ai and colleagues studying 1014 patients, 888 (88\%) with a positive chest CT scan and 601 with a positive RT-PCR for COVID-19, described $97 \%, 25 \%, 65 \%$, and $83 \%$ of sensitivity, specificity, PPV, and NPV for the CT scan, respectively. The relatively high sensitivity and low specificity in this study might be related to the low odds ratio of positive RT-PCR, considered as the reference test ${ }^{69}$, as suggested by the World Health Organization $(\mathrm{WHO})^{70}$.

Some patients have typical chest CT scan findings and symptoms for COVID-19 but their initial RT-PCR results were negative agreeing with previous research reports ${ }^{19,36,44}$. Fang et al. described 15 out of 51 patients who have an initial negative RT-PCR while their chest CT scan was positive ${ }^{36,44}$, so it is very important to pay attention to chest CT scan, epidemiologic features, and clinical symptoms. Furthermore, a combination of humoral (IgGIgM antibody) and cellular immunity, in addition to RT-PCR could refine the detection of COVID-1923,49. 


\begin{tabular}{|c|c|c|c|c|c|c|}
\hline N. & 1st author & Country (city) & Gender $\%$ male & Age (mean, range, year) & Type of study & Sample size \\
\hline 1 & Adam Bernheim $^{1}$ & United States (New York) & $50 \%$ & $45,18-80$ & Case-series & 121 \\
\hline 2 & Chun Shuang Guan ${ }^{8}$ & China (Beijing) & $47 \%$ & $42,1-86$ & Case-series & 53 \\
\hline 3 & Chunbao $\mathrm{Xie}^{8}$ & China (Chengdu) & $58 \%$ & $33,8-62$ & Cross-sectional & 19 \\
\hline 4 & Dahai Zhao ${ }^{9}$ & China (Anhui) & $50 \%$ & $42,27-56$ & Cohort & 34 \\
\hline 5 & Damiano Caruso $^{10}$ & Italy (Rome) & $53 \%$ & $57,18-89$ & Case-series & 158 \\
\hline 6 & Dehan Liu ${ }^{11}$ & China (Wuhan) & $0 \%$ & $32,23-40$ & Case-series & 15 \\
\hline 7 & Domenico Albano ${ }^{12}$ & Italy (Brescia) & $29 \%$ & $65,55-79$ & Case-series & 7 \\
\hline 8 & Fang Zheng ${ }^{11}$ & China (Wuhan) & $56 \%$ & $3,2-9$ & Case-series & 25 \\
\hline 9 & Fengxiang Song $^{13}$ & China (Shanghai) & $49 \%$ & $49,33-65$ & Case-series & 51 \\
\hline 10 & Fneg Pang $^{14}$ & China (Wuhan) & $29 \%$ & $40,25-63$ & Case-series & 21 \\
\hline 11 & Feng Kai ${ }^{15}$ & China (Shenzhen) & $33 \%$ & $8,4-14$ & Case-series & 15 \\
\hline 12 & Jasper Fuk-Woo Chan ${ }^{16}$ & China (Hong Kong) & $50 \%$ & $46,33-66$ & Case-series & 6 \\
\hline 13 & Guangming $\mathrm{Ye}^{17}$ & China (Wuhan) & $40 \%$ & $32,27-42$ & Case-series & 5 \\
\hline 14 & Guo-Qing Qian ${ }^{18}$ & China (Ningbo) & $41 \%$ & $50,5-96$ & Case-series & 91 \\
\hline 15 & Harrison X. Bai ${ }^{19}$ & China (Changsha) & NS & NS & Cohort & 256 \\
\hline 16 & Heshui Shi ${ }^{18}$ & China (Wuhan) & $52 \%$ & $49.5,39-61$ & Case-series & 81 \\
\hline 17 & Huanhuan $\operatorname{Liu}^{20}$ & China (Shanghai) & $14 \%$ & 20 (2 month-58 years) & Case-series & 51 \\
\hline 18 & Huijun Chen ${ }^{21}$ & China (Wuhan) & $0 \%$ & $30,26-40$ & Case-series & 9 \\
\hline 19 & Jian $\mathrm{Wu}^{22}$ & China (Yuncheng) & $49 \%$ & $46,4->65$ & Case-series & 80 \\
\hline 20 & Jianhua Xia $\mathrm{MM}^{23}$ & China (Zhejiang) & $70 \%$ & $54.5,13-74$ & Cross-sectional & 30 \\
\hline 21 & Junqing $\mathrm{Xu}^{24}$ & China (Shenzhen) & $0 \%$ & $52,45-65$ & Case-series & 3 \\
\hline 22 & $\mathrm{KC} \mathrm{Liu}^{22}$ & China (Hefei) & $51 \%$ & $42,5-86$ & Cohort & 73 \\
\hline 23 & Pinggui Lei ${ }^{25}$ & China (Guiyang) & $57 \%$ & $47(12-83)$ & Case-series & 14 \\
\hline 24 & $\mathrm{Li} \mathrm{Guo}^{23}$ & China (Beijing) & $50 \%$ & $35,2-64$ & Cross-sectional & 6 \\
\hline 25 & Li Yuanyuan ${ }^{26}$ & China (Wuhan) & $46 \%$ & $52,25-82$ & Cross-sectional & 54 \\
\hline 26 & Lia $\mathrm{Na} \mathrm{Ji}^{27}$ & China (Beijing) & NS & NS & Case-series & 7 \\
\hline 27 & Lisi Deng $^{28}$ & china (Zhuha) & NS & $\geq 18$ year & Cohort & 56 \\
\hline 28 & Heng Meng $^{26}$ & China (Wuhan) & $45 \%$ & 43 & Case-series & 58 \\
\hline 29 & Michael Chung $^{29}$ & United States (New York) & $61 \%$ & $51,29-77$ & Case-series & 21 \\
\hline 30 & Mingzhi $\mathrm{Li}^{30}$ & China (Nanchang) & $55.5 \%$ & $43,31-68$ & Case-series & 9 \\
\hline 31 & Nanshan Chen ${ }^{31}$ & China (Wuhan) & $68 \%$ & $55.5,21-82$ & Case-series & 99 \\
\hline 32 & Qi Zhong $^{32}$ & China (Wuhan) & $23 \%$ & $32,28-35$ & Cohort & 93 \\
\hline 33 & Qinxue Shen ${ }^{33}$ & China (Hunan) & $33 \%$ & $8,1-12$ & Case-series & 9 \\
\hline 34 & Rui $\operatorname{Han}^{34}$ & China (Wuhan) & $35 \%$ & $45,21-95$ & Case-series & 108 \\
\hline 35 & Ruirui Wang ${ }^{33}$ & China (Anhui) & $57 \%$ & $39,1-80$ & Case-series & 125 \\
\hline 36 & Ruoqing Li ${ }^{35}$ & China (Chongqing) & $53 \%$ & 50 & Case-series & 225 \\
\hline 37 & Shuchang Zhou ${ }^{34}$ & China (Wuhan) & $63 \%$ & $53,30-77$ & Case-series & 118 \\
\hline 38 & Siyu Chen ${ }^{36}$ & China (Chongqing) & $0 \%$ & $29,25-31$ & Case-series & 5 \\
\hline 39 & Soon Ho Yoon ${ }^{37}$ & Korea (Seoul) & $44 \%$ & 54 & Case-series & 9 \\
\hline 40 & Suxin Wan ${ }^{38}$ & China (Chongqing) & $53 \%$ & $47,36-55$ & Cross-sectional & 135 \\
\hline 41 & $\mathrm{Tao}_{\mathrm{Ai}}{ }^{36}$ & China (Wuhan) & $46 \%$ & $51,2-95$ & Cross-sectional & 1014 \\
\hline 42 & Tao $\mathrm{Lu}^{32}$ & China (Sichuan) & $20 \%$ & $52,41-62$ & Case-series & 5 \\
\hline 43 & Tianmin $\mathrm{Xu}^{39}$ & China (Changzhou) & $49 \%$ & $42,24-65$ & Cohort & 51 \\
\hline 44 & Wanbo Zhu ${ }^{34}$ & China (Hefei) & $48 \%$ & $40,27-53$ & Case-series & 116 \\
\hline 45 & Wang $\mathrm{XF}^{33}$ & China (Shenzhen) & $41 \%$ & 9 & Case-series & 34 \\
\hline 46 & Wei $\mathrm{Li}^{18}$ & China (Zhuhai) & $80 \%$ & 3 (10 month-6 years) & Case-series & 5 \\
\hline 47 & Wenjie Yang $^{38}$ & China (Shanghai) & $54 \%$ & 45 & Case-series & 149 \\
\hline 48 & Wu Jing ${ }^{40}$ & China (Nanjing) & $40 \%$ & $52,25-80$ & Case-series & 130 \\
\hline 49 & $\mathrm{Xi} \mathrm{Xu}^{41}$ & China (Guangzhou) & $43 \%$ & $50,18-86$ & Case-series & 90 \\
\hline 50 & Xiang Dong $^{31}$ & China (Wuhan) & $45 \%$ & $37(2-69)$ & Case-series & 11 \\
\hline 51 & Xiao-ying $\mathrm{Xia}^{42}$ & China (Chongqing) & $60 \%$ & $56.5,43-71$ & Case-series & 10 \\
\hline 52 & Xiaoli Zhang ${ }^{43}$ & China (Zhejiang) & $51 \%$ & 46 & Cross-sectional & 645 \\
\hline 53 & Xiaoqing $\mathrm{Wu}^{43}$ & China (Wuhan) & $0 \%$ & $29,21-36$ & Case-series & 23 \\
\hline 54 & Xingzhi Xie $^{44}$ & China (Changsha) & NS & NS & Cross-sectional & 167 \\
\hline 55 & Xiong Zeng ${ }^{40}$ & China (Changsha) & NS & NS & Cross-sectional & 47 \\
\hline 56 & Yicheng Fang ${ }^{44}$ & China (Shanghai) & $57 \%$ & $45,39-55$ & Case-series & 51 \\
\hline
\end{tabular}




\begin{tabular}{|l|l|l|l|l|l|c|}
\hline N. & 1st author & Country (city) & Gender\% male & Age (mean, range, year) & Type of study & Sample size \\
\hline 57 & Yifei Chen ${ }^{45}$ & China (Wuhan) & $36 \%$ & $51(42-62)$ & Case-series & 42 \\
\hline 58 & Yueying Pan ${ }^{46}$ & China (Wuhan) & $52 \%$ & 45 & Case-series & 63 \\
\hline 59 & Zenghui Cheng ${ }^{46}$ & China (Shanghai) & NS & NS & Cross-sectional & 38 \\
\hline 60 & Zhang $\mathrm{MQ}^{47}$ & China (Beijing) & $56 \%$ & $36,15-49$ & Case-series & 9 \\
\hline
\end{tabular}

Table 1. Data of 60 included studies in the data extraction step. NS not stated.

The results of Chan and colleagues indicated that among 273 specimens (15 COVID-19 positives), the RdRp$\mathrm{P} 2$ test showed 77 positive specimens and the RdRp/Hel test showed 42 positives. Moreover, RdRp/Hel analysis did not cross-reacted with any human coronaviruses or other respiratory pathogens while RdRp-P2 analysis reacted to SARS-CoV either ${ }^{71}$. Another study expressed that the sensitivity of $\mathrm{N}$ gene assay in finding the positive samples is 10 times higher than the ORF-1b gene assay ${ }^{72}$.

In February, 280 suspected patients with clinical manifestations of COVID-19 were tested in the Marseille hospital. None of the patients were positive for SARS-COV-2 ${ }^{73}$. Guo-Qing Qian et al. reported that all the patients, except three of them, were confirmed with the second RT-PCR test ${ }^{18}$. In the study by Tao Ai et al., it is highlighted that out of 1014 patients, 308 patients with negative PCR results, were strongly perceived as infected by clinical manifestations and CT scans. The percentage of a positive test for the first, second, third, and fourth tests were $37.7 \%, 22.6 \%, 5 \%$, and $0.9 \%$, respectively. Unfortunately, about $33.9 \%$ of the patients could not be diagnosed even with the fourth test. CT scans were positive in 580 of 601 (97\%) COVID-19 confirmed patients by the RT-PCR test and in 308 of 413(74.6\%) patients with negative RT-PCR assay ${ }^{74}$. In a retrospective analysis, among 51 patients, $98 \%(50 / 51)$ had abnormal CT, besides $70.6 \%(36 / 51)$ had positive PCR assay initially and about $30 \%$ of the tests became positive after second, third, and fourth scanning ${ }^{44}$.

A study of five children suggested that four children had positive PCR outcomes within the first assay, but one with COVID-19 suggestive CT findings turned positive after six times of examining ${ }^{35}$. It is also possible that negative RT-PCR with three times of repeating, turns positive on the fourth test, while CT demonstrated typical features such as $\mathrm{GGO}^{44}$. Chest CT presented rapidly developing multiple patchy consolidations and GGOs in both lungs of a case reported by J Wei, while in the later stage, there was the development of fibrosis. So with high-resolution CT, it will be easier to find GGOs in the early stage ${ }^{75}$.

What stands out from Table 2 is that $58.9 \%$ of the infected COVID-19 patients could be recognized in the first test and about $18.6 \%, 6.3 \%$ and $0.7 \%$ could be diagnosed in the further second, third and fourth tests, respectively. Besides, about $9 \%$ of the infected patients have not been detected, even after the fourth test. According to the results and due to the PCR's cost and time consumption, it seems that repeating the test up to 3 times is reasonable in patients with initially negative results (with $24 \mathrm{~h}$ to 3 days' time interval based on literature). Also, CT scan findings and clinical manifestation should be encountered in all patients, especially in suspected ones with multiple negative PCRs.

About $80 \%$ of COVID-19 patients have mild disease and just about $15 \%$ of them will reach severe stages. Positive RT-PCR results usually have a high positive predictive value, but negative RT-PCR should be repeated three times to increase the negative predictive value up to $98 \%$ (57\% at first test, $34 \%$ at second one, and $7 \%$ at third time).

If the patient's death is due to COVID-19, but their PCR is negative, even if their chest CT is positive, their cause of death would not report COVID-19. Some patients with negative PCR result die, but based on our results, $87 \%$ of them are Covid-19 positive and their disease should be confirmed by repeating PCR for up to three times.

On the other hand, the exact place of chest CT is for staging the COVID-19 disease as mild, moderate, and severe, instead of being a screening tool. Some antibody and serology testing can support the RT-PCR test. A study in two patients with COVID-19 pneumonia by Lin and colleagues indicated the presence of ground-glass lesions and patchy consolidations in repeated chest $\mathrm{CT}^{76}$. Also, the lesions were classically accompanied by bronchial bundles or subpleural lesions. In patients who have a fever but not having the previous contact with the epidemic area, the appropriate finding of the COVID-19 RNA is compulsory to guarantee the high efficacy of treatment ${ }^{76}$.

We acknowledge that our study had some limitations: (1) the specificity of CT scan was not as reliable as the sensitivity, due to the majority of studies' nature, which were case-series and the number of true negative patients in those studies were zero. (2) It has been postulated in Bernheim et al's study that the chance of detecting lung involvement in chest CT scan will be increased if the duration between symptom onset and initial chest CT scan rises and this duration was different among 60 studies. 
Study

Adam Bernheim 2020

Chu Shuang Guan 2020

Chunbao Xie 2020

Dahai Zhao 2020

Damiano Caruso 2020

Dehan Liu 2020

Dumenico Albano 2020

Fang ZHENG 2020

Fenxiang Song 2020

Fneg Pang 2020

Freng K 2020

Fuk-Woo Chan 2020

Guanming Ye 2020

Guo-Qing Qian 2020

Harrison X.Bai 2020

Heshui Shi 2020

Huanhuan Liu 2020

Huijun Chen 2020

Jian Wu 2020

Jianhua Xia MM 2020

Junqing Xu 2020

KC liu 2020

Lei Pinggui 2020

Li Guo 2020

Li YY 2020

Lia Na J 2020

Lisi Deng 2020

Meng Heng 2020

Michael Chung 2020

Mingzhi Li 2020

Nanshan Chen 2020

Qi Zhong 2020

Qinxue Shen 2020

Rui Han 2020

Ruirui Wang 2020

Ruoqing Li 2020

Shuchang Zhou 2020

Siyu Chen 2020

Soon Ho Yoon 2020

Suxin Wan 2020

Tao Ai 2020

Tao Lu 2020

Tianmin Xu 2020

Wanboo Zhu 2020

Wang XF 2020

Wei Li 2020

Wenjie Yang 2020

Wu J 2020

XI Xu 2020

Xiang Dong 2020

Xiao-ying Xia 2020

Xiaoli Zhang 2020

Xiaoqing Wu 2020

Xingzhi Xie 2020

XiongAzeng 2020

Yicheng Fang 2020

Yifei Chen 2020

Yueying Pan 2020

Zenghui Cheng 2020

Zhang MQ 2020

\begin{tabular}{|c|c|c|c|c|c|}
\hline TP & FP & FN & TN & Sensitivity & Specificity \\
\hline 94 & 0 & 27 & 0 & $0.78[0.69,0.85]$ & Not estimable \\
\hline 47 & 0 & 6 & 0 & $0.89[0.77,0.96]$ & Not estimable \\
\hline 9 & 5 & 0 & 5 & $1.00[0.66,1.00]$ & $0.50[0.19,0.81]$ \\
\hline 19 & 15 & 0 & 0 & $1.00[0.82,1.00]$ & $0.00[0.00,0.22]$ \\
\hline 60 & 42 & 2 & 0 & $0.97[0.89,1.00]$ & $0.00[0.00,0.08]$ \\
\hline 15 & 0 & 0 & 0 & $1.00[0.78,1.00]$ & Not estimable \\
\hline 5 & 2 & 0 & 0 & $1.00[0.48,1.00]$ & $0.00[0.00,0.84]$ \\
\hline 17 & 0 & 8 & 0 & $0.68[0.46,0.85]$ & Not estimable \\
\hline 51 & 0 & 0 & 0 & $1.00[0.93,1.00]$ & Not estimable \\
\hline 17 & 0 & 4 & 0 & $0.81[0.58,0.95]$ & Not estimable \\
\hline 9 & 0 & 6 & 0 & $0.60[0.32,0.84]$ & Not estimable \\
\hline 5 & 1 & 0 & 1 & $1.00[0.48,1.00]$ & $0.50[0.01,0.99]$ \\
\hline 5 & 0 & 0 & 0 & $1.00[0.48,1.00]$ & Not estimable \\
\hline 83 & 3 & 5 & 0 & $0.94[0.87,0.98]$ & $0.00[0.00,0.71]$ \\
\hline 219 & 0 & 37 & 0 & $0.86[0.81,0.90]$ & Not estimable \\
\hline 81 & 0 & 0 & 0 & $1.00[0.96,1.00]$ & mable \\
\hline 30 & 17 & 4 & 0 & $0.88[0.73,0.97]$ & 0.00 \\
\hline 8 & 0 & 1 & 0 & $0.89[0.52,1.00]$ & Not estimable \\
\hline 55 & 0 & 25 & 0 & $0.69[0.57,0.79]$ & timable \\
\hline 30 & 0 & 0 & 0 & $1.00[0.88,1.00]$ & timable \\
\hline 3 & 0 & 0 & 0 & $1.00[0.29,1.00]$ & imable \\
\hline 70 & 0 & 3 & 0 & $0.96[0.88,0.99]$ & Not estimable \\
\hline 10 & 0 & 4 & 0 & $0.71[0.42,0.92]$ & Not estimable \\
\hline 1 & 2 & 1 & 1 & $0.50[0.01,0.99]$ & $0.33[0.01,0.91]$ \\
\hline 31 & 23 & 0 & 0 & $1.00[0.89,1.00]$ & $0.00[0.00,0.15]$ \\
\hline 1 & 1 & 3 & 2 & $0.25[0.01,0.81]$ & $0.67[0.09,0.99]$ \\
\hline 37 & 0 & 19 & 0 & $0.66[0.52,0.78]$ & Not estimable \\
\hline 58 & 0 & 0 & 0 & $1.00[0.94,1.00]$ & Not estimable \\
\hline 18 & 0 & 3 & 0 & $0.86[0.64,0.97]$ & Not estimable \\
\hline 9 & 0 & 0 & 0 & $1.00[0.66,1.00]$ & Not estimable \\
\hline 99 & 0 & 0 & 0 & $1.00[0.96,1.00]$ & Not estimable \\
\hline 50 & 0 & 4 & 39 & $0.93[0.82,0.98]$ & $1.00[0.91,1.00]$ \\
\hline 2 & 0 & 7 & 0 & $0.22[0.03,0.60]$ & Not estimable \\
\hline 108 & 0 & 0 & 0 & $1.00[0.97,1.00]$ & Not estimable \\
\hline 120 & 0 & 5 & 0 & $0.96[0.91,0.99]$ & Not estimable \\
\hline 225 & 0 & 0 & 0 & $1.00[0.98,1.00]$ & Not estimable \\
\hline 62 & 56 & 0 & 0 & $1.00[0.94,1.00]$ & $0.00[0.00,0.06]$ \\
\hline 5 & 0 & 0 & 0 & $1.00[0.48,1.00]$ & Not estimable \\
\hline 9 & 0 & 0 & 0 & $1.00[0.66,1.00]$ & Not estimable \\
\hline 135 & 0 & 0 & 0 & $1.00[0.97,1.00]$ & Not estimable \\
\hline 580 & 308 & 21 & 105 & $0.97[0.95,0.98]$ & $0.25[0.21,0.30]$ \\
\hline 5 & 0 & 0 & 0 & $1.00[0.48,1.00]$ & Not estimable \\
\hline 49 & 2 & 0 & 0 & $1.00[0.93,1.00]$ & $0.00[0$. \\
\hline 30 & 56 & 2 & 28 & $0.94[0.79,0.99]$ & $0.33[0.23,0.44]$ \\
\hline 34 & 0 & 0 & 0 & $1.00[0.90,1.00]$ & Not estimable \\
\hline 2 & 1 & 2 & 0 & $0.50[0.07,0.93]$ & $0.00[0.00,0.97]$ \\
\hline 132 & 0 & 17 & 0 & $0.89[0.82,0.93]$ & Not estimable \\
\hline 130 & 0 & 0 & 0 & $1.00[0.97,1.00]$ & Not estimable \\
\hline 69 & 0 & 21 & 0 & $0.77[0.67,0.85]$ & timable \\
\hline 7 & 1 & 2 & 1 & $0.78[0.40,0.97]$ & $0.50[0.01,0.99]$ \\
\hline 10 & 0 & 0 & 0 & $1.00[0.69,1.00]$ & Not estimable \\
\hline 573 & 0 & 72 & 0 & $0.89[0.86,0.91]$ & Not estimable \\
\hline 19 & 4 & 0 & 0 & $1.00[0.82,1.00]$ & $0.00[0.00,0.60]$ \\
\hline 155 & 5 & 7 & 0 & $0.96[0.91,0.98]$ & $0.00[0.00,0.52]$ \\
\hline 19 & 8 & 1 & 19 & $0.95[0.75,1.00]$ & $0.70[0.50,0.86]$ \\
\hline 35 & 15 & 1 & 0 & $0.97[0.85,1.00]$ & $0.00[0.00,0.22]$ \\
\hline 40 & 0 & 2 & 0 & $0.95[0.84,0.99]$ & Not estimable \\
\hline 63 & 0 & 0 & 0 & $1.00[0.94,1.00]$ & Not estimable \\
\hline 11 & 22 & 0 & 5 & $1.00[0.72,1.00]$ & $0.19[0.06,0.38]$ \\
\hline & 0 & 2 & 0 & $0.78[0.40,0.97]$ & Not estimable \\
\hline
\end{tabular}

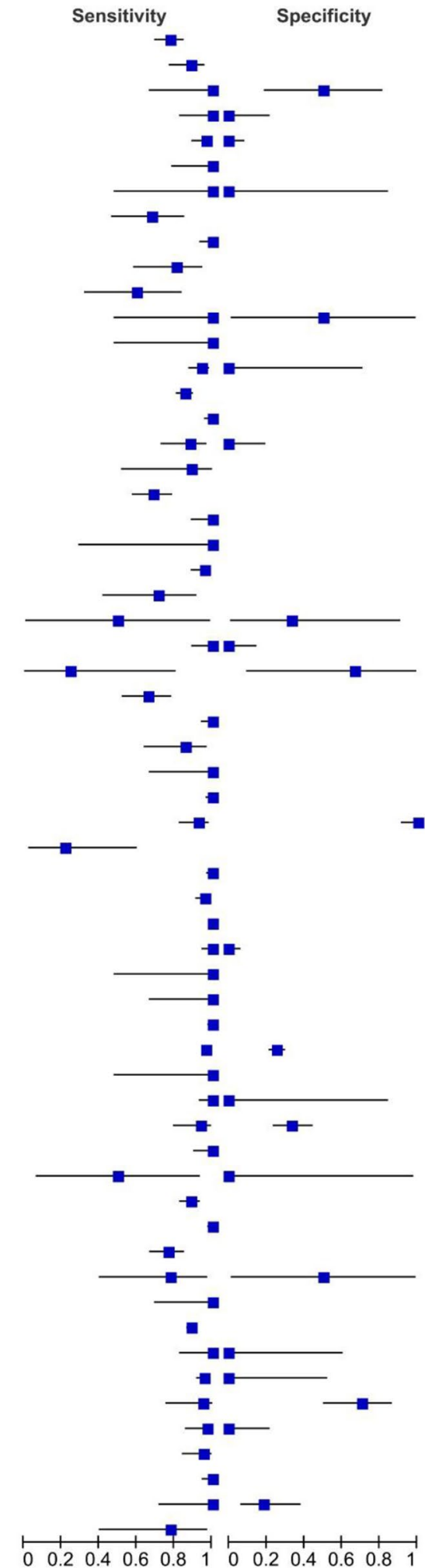

Figure 2. Sensitivity and specificity of 60 included studies. 


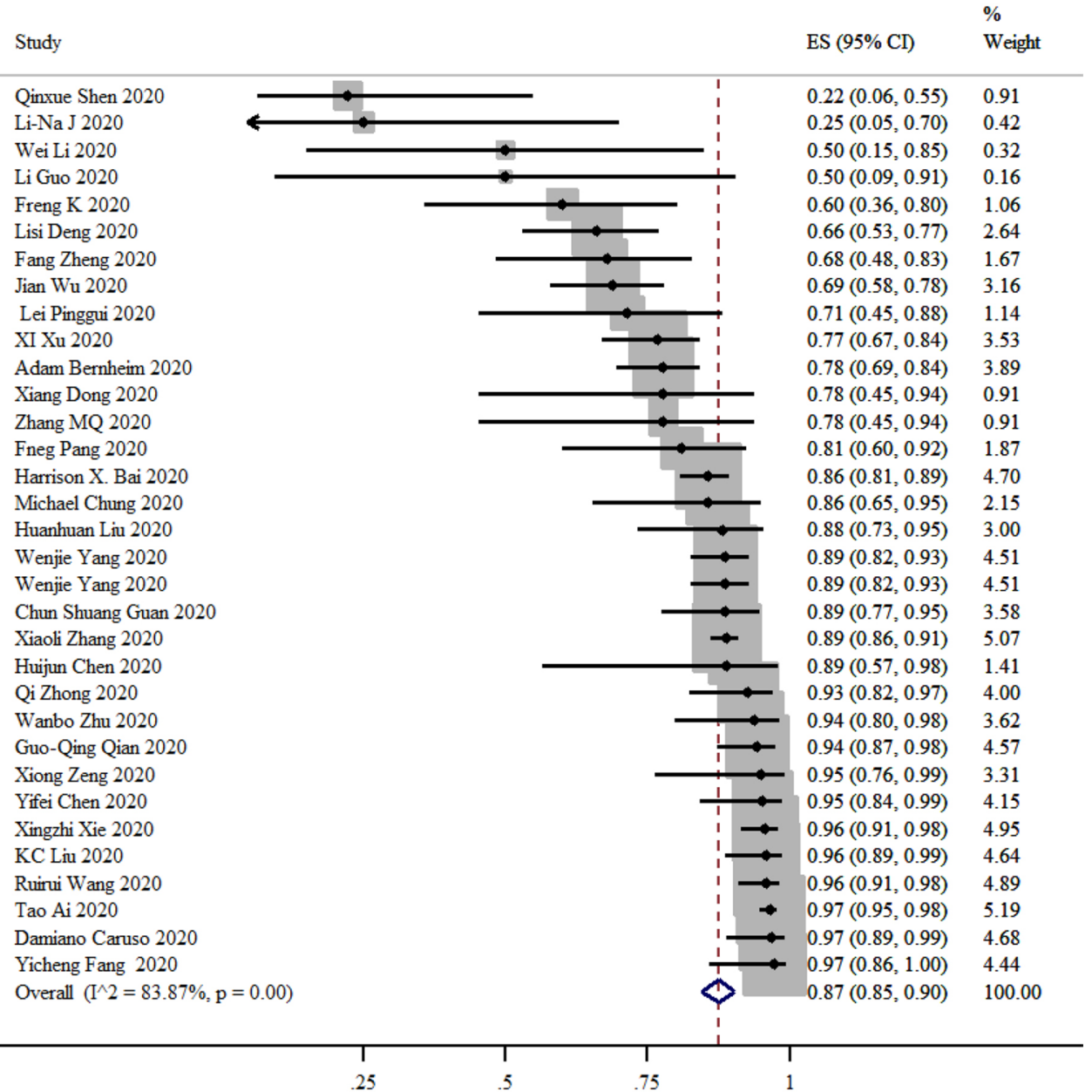

Figure 3. Summary of sensitivity and 95\% CI, generated by the STATA.

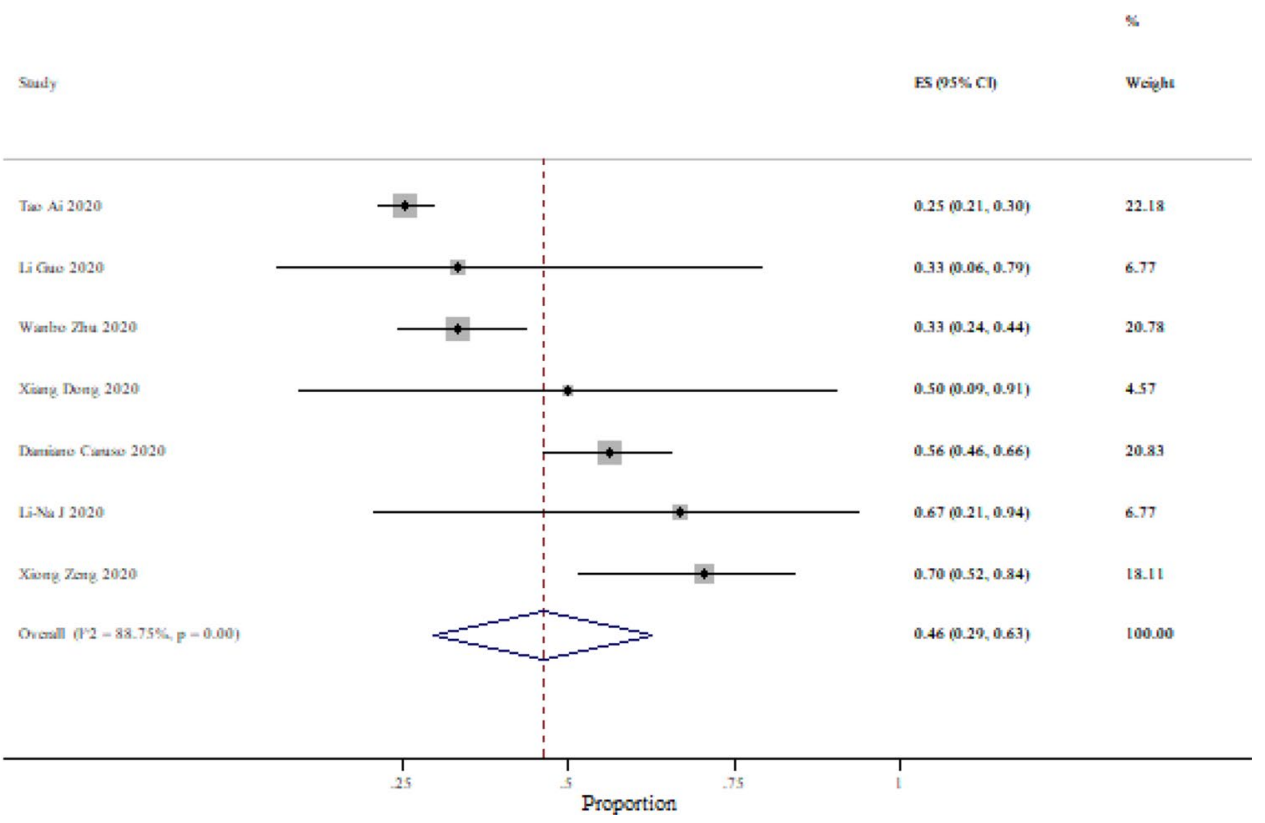

Figure 4. Summary of specificity and $95 \% \mathrm{CI}$, generated by the STATA. 


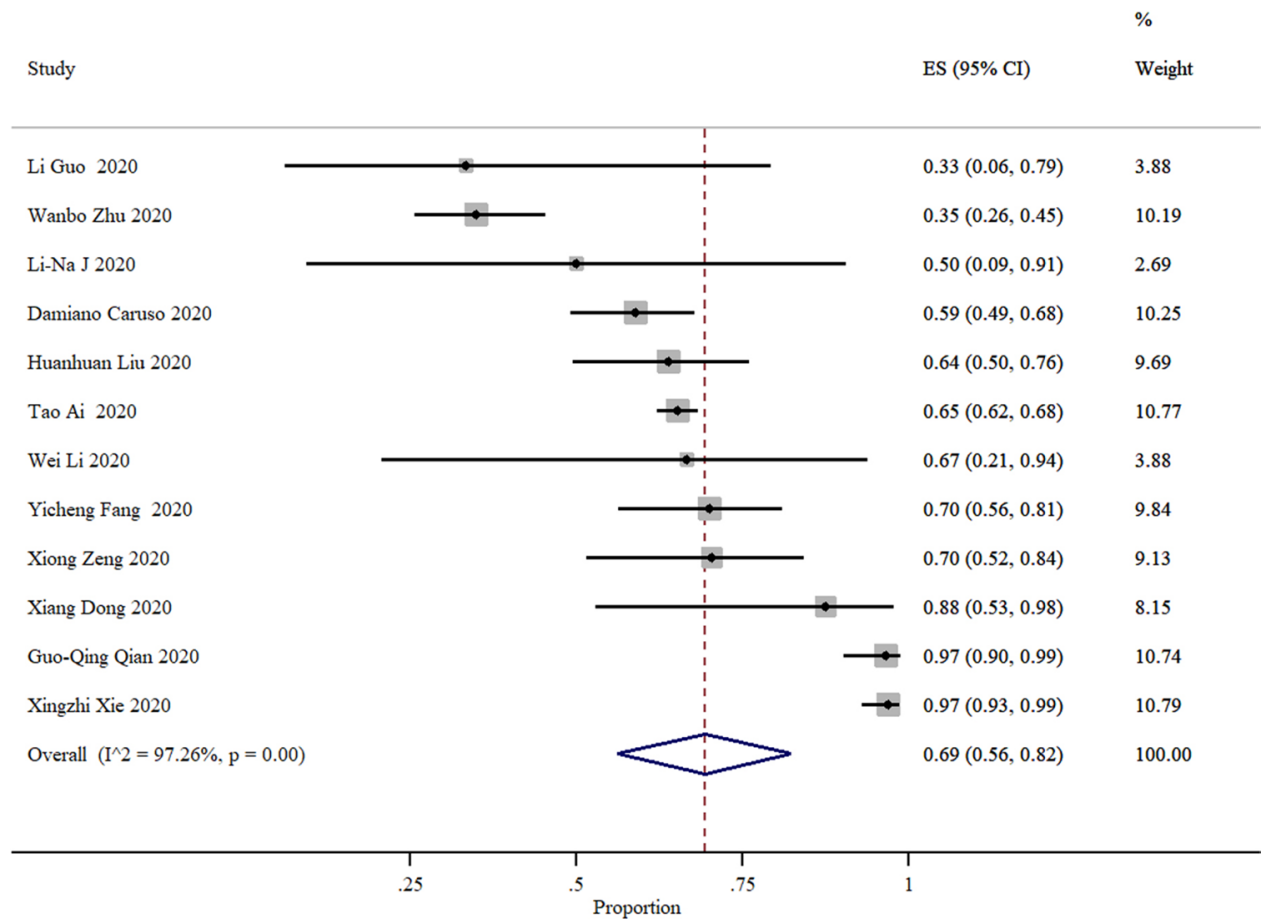

Figure 5. Summary of positive predictive value and $95 \%$ CI of 18 studies, generated by the STATA.

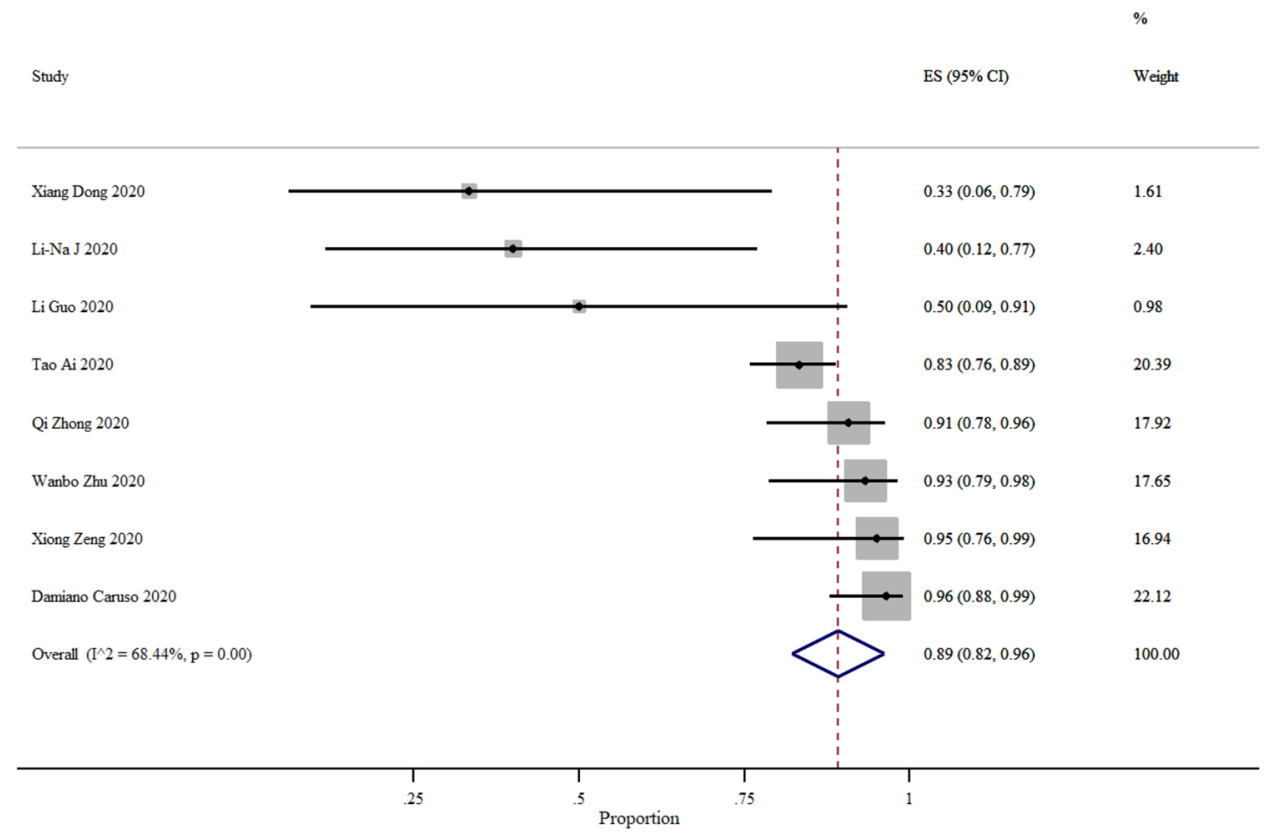

Figure 6. Summary of negative predictive value and $95 \%$ CI of six studies, generated by the STATA. 


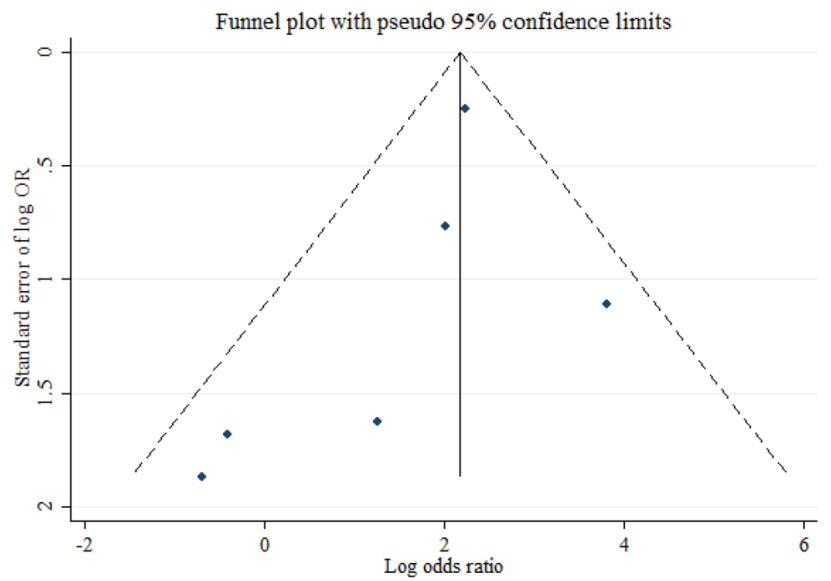

Figure 7. The Deeks' funnel plot curve for assessment of publication bias.

\begin{tabular}{|c|c|c|c|c|c|c|c|c|}
\hline N. & First author & N. of total cases & $\begin{array}{l}\text { Number of total confirmed } \\
\text { patients }\end{array}$ & $\begin{array}{l}\text { N. of patients confirmed } \\
\text { with the first RT-PCR test } \\
\text { (perc. }{ }^{2} \text { ) }\end{array}$ & $\begin{array}{l}\text { N. of patients confirmed } \\
\text { with the second RT-PCR } \\
\text { test (perc.') }\end{array}$ & $\begin{array}{l}\text { N. of patients confirmed } \\
\text { with the third RT-PCR test } \\
\text { (perc.) }\end{array}$ & $\begin{array}{l}\text { N. of patients confirmed } \\
\text { with the fourth RT-PCR } \\
\text { test (perc. }{ }^{\text {) }}\end{array}$ & $\begin{array}{l}\text { N. of Patients confirmed } \\
\text { later (perc. } \text {. }^{\text {s }}\end{array}$ \\
\hline 1 & Tao $\mathrm{Ai}^{36}$ & 1014 & 909 & $343(37.7 \%)$ & $205(22.6 \%)$ & $45(5 \%)$ & $8(0.9 \%)$ & $308(33.9 \%)$ \\
\hline 2 & Xingzhi Xie ${ }^{44}$ & 167 & 167 & $162(97 \%)$ & $2(1.2 \%)$ & $2(1.2 \%)$ & $0(0 \%)$ & $1(0.6 \%)$ \\
\hline 3 & Jian $\mathrm{Wu}^{22}$ & 80 & 80 & $41(51.2 \%)$ & $30(37.5 \%)$ & $9(11.3 \%)$ & $0(0 \%)$ & $0(0 \%)$ \\
\hline 4 & Anne Kimball ${ }^{148}$ & 82 & 76 & $23(30 \%)$ & $-f^{f}$ & - & - & $53(70 \%)$ \\
\hline 5 & Li Yuanyuan ${ }^{49}$ & 54 & 54 & $31(57 \%)$ & - & - & - & $23(42.6 \%)$ \\
\hline 6 & Chenyao $\operatorname{Lin}^{50}$ & 52 & 52 & $23(44 \%)$ & - & - & - & $29(56 \%)$ \\
\hline 7 & Yicheng Fang ${ }^{44}$ & 51 & 51 & $36(70.6 \%)$ & $12(23.6 \%)$ & $2(7.8 \%)$ & $1(2 \%)$ & $0(0 \%)$ \\
\hline 8 & Qi Zhong $^{32}$ & 49 & 49 & $13(26.5 \%)$ & - & - & - & $36(73.5 \%)$ \\
\hline 9 & Lorenzo Azzi & 25 & 25 & $23(92 \%)$ & $2(8 \%)$ & - & - & $0(0 \%)$ \\
\hline 10 & Xiaoqing $\mathrm{Wu}^{43}$ & 23 & 23 & $19(83 \%)$ & - & - & - & $4(17 \%)$ \\
\hline 11 & Qing Chen ${ }^{52}$ & 9 & 9 & $9(100 \%)$ & - & - & - & $0(0 \%)$ \\
\hline 12 & Li-Na Ji ${ }^{27}$ & 7 & 5 & $4(80 \%)$ & - & - & - & $1(20 \%)$ \\
\hline 13 & Jasper Fuk-Woo Chan ${ }^{16}$ & 6 & 5 & $4(80 \%)$ & - & - & - & $1(20 \%)$ \\
\hline 14 & YajunYuan $^{53}$ & 6 & 6 & $6(100 \%)$ & - & - & - & $0(0 \%)$ \\
\hline 15 & Wei $\mathrm{Li}^{18}$ & 5 & 5 & $4(80 \%)$ & $0(0 \%)$ & $0(0 \%)$ & $0(0 \%)$ & $1(20 \%)$ \\
\hline 16 & Zohre Khodamoradi ${ }^{54}$ & 4 & 4 & $4(100 \%)$ & - & - & - & $0(0 \%)$ \\
\hline 17 & $\operatorname{Li~N}^{55}$ & 3 & 3 & $1(33.3 \%)$ & $0(0 \%)$ & $0(0 \%)$ & - & $2(66.7 \%)$ \\
\hline 18 & Junqing $\mathrm{Xu}^{24}$ & 3 & 3 & $0(0 \%)$ & $2(67 \%)$ & $1(33 \%)$ & - & $0(0 \%)$ \\
\hline 19 & Yuanzhe $\mathrm{Li}^{41}$ & 2 & 2 & $1(50 \%)$ & $1(50 \%)$ & - & - & $0(0 \%)$ \\
\hline 20 & Michal Paret $^{56}$ & 2 & 2 & $2(100 \%)$ & - & - & - & $0(0 \%)$ \\
\hline 21 & Zhi-Qun Mao $^{57}$ & 2 & 2 & $2(100 \%)$ & - & - & - & $0(0 \%)$ \\
\hline 22 & Wendong $\mathrm{Hao}^{44}$ & 1 & 1 & $0(0 \%)$ & $0(0 \%)$ & $0(0 \%)$ & $1(100 \%)$ & $0(0 \%)$ \\
\hline 23 & Peikai Huang ${ }^{40}$ & 1 & 1 & $0(0 \%)$ & $0(0 \%)$ & $1(100 \%)$ & - & $0(0 \%)$ \\
\hline 24 & Jinrong $\mathrm{Qu}^{58}$ & 1 & 1 & $1(100 \%)$ & - & - & - & $0(0 \%)$ \\
\hline 25 & Xavier Marchand-Senécal ${ }^{59}$ & 1 & 1 & $1(100 \%)$ & - & - & - & $0(0 \%)$ \\
\hline 26 & Takeshi Arashiro $^{55}$ & 1 & 1 & $1(100 \%)$ & - & - & - & $0(0 \%)$ \\
\hline 27 & Hao Feng ${ }^{30}$ & 1 & 1 & $0(0 \%)$ & $0(0 \%)$ & $0(0 \%)$ & $0(0 \%)$ & $1(100 \%)$ \\
\hline 28 & Ryota Hase ${ }^{60}$ & 1 & 1 & $0(0 \%)$ & $1(100 \%)$ & - & - & $0(0 \%)$ \\
\hline 29 & Yosuke Hirotsu ${ }^{61}$ & 1 & 1 & $1(100 \%)$ & - & - & - & $0(0 \%)$ \\
\hline 30 & E. Kalafat ${ }^{62}$ & 1 & 1 & $0(0 \%)$ & $1(100 \%)$ & - & - & $0(0 \%)$ \\
\hline 31 & Mojtaba Kamali Aghdam ${ }^{63}$ & 1 & 1 & $1(100 \%)$ & - & - & - & $0(0 \%)$ \\
\hline 32 & Parisa Karami6 ${ }^{64}$ & 1 & 1 & $1(100 \%)$ & - & - & - & $0(0 \%)$ \\
\hline 33 & Dasheng $\mathrm{Li}^{7}$ & 1 & 1 & $0(0 \%)$ & $0(0 \%)$ & $1(100 \%)$ & - & $0(0 \%)$ \\
\hline 34 & Ding-feng $\mathrm{Lv}^{65}$ & 1 & 1 & $0(0 \%)$ & $0(0 \%)$ & $1(100 \%)$ & $1(100 \%)$ & $1(100 \%)$ \\
\hline 35 & Chaisith Sivakorn $^{66}$ & 1 & 1 & $0(0 \%)$ & $1(100 \%)$ & - & - & $0(0 \%)$ \\
\hline
\end{tabular}

Table 2. The number of positive test results in RT-PCR testing and the number of confirmed ones. ${ }^{\mathrm{a}}$ Number of primarily confirmed patients divided total confirmed patients. ${ }^{b}$ Number of secondary confirmed patients divided total confirmed patients. ${ }^{c}$ Number of thirdly confirmed patients divided total confirmed patients. ${ }^{\mathrm{d}}$ Number of fourthly confirmed patients divided total confirmed patients. ${ }^{\mathrm{e}}$ Number of patients who were

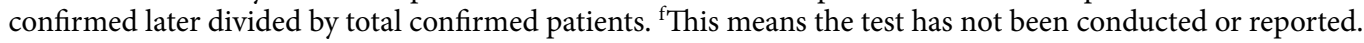




\begin{tabular}{|c|c|c|c|c|c|c|c|}
\hline N. & First author & Total N. of cases & $\begin{array}{l}\text { N. of patients } \\
\text { confirmed with the first } \\
\text { RT-PCR test }\end{array}$ & $\begin{array}{l}\text { N. patients confirmed } \\
\text { later }\end{array}$ & $\begin{array}{l}\text { Primarily confirmed } \\
\text { patients divided total } \\
\text { confirmed patients (\%) }\end{array}$ & $\begin{array}{l}\text { Number of sets (primer } \\
\text { and probe) }\end{array}$ & Type of genes \\
\hline 1 & Jian $\mathrm{Wu}^{22}$ & 80 & 41 & 39 & 51.2 & 2 & $\mathrm{~N}$ and ORF1ab \\
\hline 2 & Anne Kimball ${ }^{48}$ & 82 & 23 & 53 & 30 & 2 & $\mathrm{~N}$ \\
\hline 3 & Chenyao $\operatorname{Lin}^{50}$ & 52 & 23 & 29 & 44 & 2 & $\mathrm{~N}$ and ORF1ab \\
\hline 4 & Qing Chen $^{52}$ & 9 & 9 & 0 & 100 & 3 & RdRP, $\mathrm{E}$ and $\mathrm{N}$ \\
\hline 5 & Jasper Fuk-Woo Chan ${ }^{16}$ & 6 & 4 & 1 & 80 & 2 & RdRP and $S$ \\
\hline 6 & Wendong $\mathrm{Hao}^{44}$ & 1 & 0 & 1 & 0 & 1 & ORF1ab \\
\hline 7 & $\begin{array}{l}\text { Xavier Marchand- } \\
\text { Senécal }^{59}\end{array}$ & 1 & 1 & 0 & 100 & 1 & RdRP \\
\hline 8 & Yosuke Hirotsu $^{61}$ & 1 & 1 & 0 & 100 & 7 & N gene \\
\hline 9 & Ding-feng Lv $v^{65}$ & 1 & 0 & 1 & 0 & 1 & ORFlab or N gene \\
\hline
\end{tabular}

Table 3. From the information illustrated in Table 2, those which their primer and probe's data were available.

In conclusion, the results of the present systematic review and meta analysis shed new light on the comparison between chest-CT scan and rRT-PCR validity in terms of diagnosis in patients with COVID-19. Due to lower diagnostic sensitivity of chest-CT scan in comparison to rRT-PCR, performing rRT-PCR is mandatory for any individuals with suspicious symptoms. Nevertheless, the initial negative rRT-PCR result is not fully able to roll out COVID-19 in all cases and because of that, repeating the test for three times is vital to roll out COVID-19.

\section{Data availability}

Information, data, and photos will be provided if they are requested.

Received: 6 May 2020; Accepted: 16 December 2020

Published online: 28 December 2020

\section{References}

1. Bernheim, A. et al. Chest CT findings in coronavirus disease-19 (COVID-19): Relationship to duration of infection. Radiology https://doi.org/10.1148/radiol.2020200463 (2020).

2. Organization, W. H. Coronavirus disease 2019 ( COVID-19): situation report, 92 (2020).

3. Wu, Z. \& McGoogan, J. M. Characteristics of and important lessons from the coronavirus disease 2019 (COVID-19) outbreak in China: Summary of a report of 72314 cases from the Chinese Center for Disease Control and Prevention. JAMA 323, 1239-1242 (2020).

4. Corman, V. M. et al. Detection of 2019 novel coronavirus (2019-nCoV) by real-time RT-PCR. Eurosurveillance 25, 2000045 (2020).

5. Rubin, E. J., Baden, L. R., Morrissey, S. \& Campion, E. W. Medical journals and the 2019-nCoV outbreak. N. Engl. J. Med. 382, $10-15(2020)$.

6. Loeffelholz, M. J., \& Tang, Y. W. Laboratory diagnosis of emerging human coronavirus infections-the state of the art. Emerg. Microbes. Infect. 9(1), 747-756 (2020).

7. Young, B. E. et al. Epidemiologic features and clinical course of patients infected with SARS-CoV-2 in Singapore. JAMA https:// doi.org/10.1001/jama.2020.3204 (2020).

8. Guan, C. S. et al. Imaging features of coronavirus disease 2019 (COVID-19): Evaluation on thin-section CT. Acad. Radiol. https ://doi.org/10.1016/j.acra.2020.03.002 (2020).

9. Zhao, D. et al. A comparative study on the clinical features of COVID-19 pneumonia to other pneumonias. Clin. Infect. Dis. https ://doi.org/10.1093/cid/ciaa247 (2020).

10. Caruso, D. et al. Chest CT features of COVID-19 in Rome, Italy. Radiology https://doi.org/10.1148/radiol.2020201237 (2020).

11. Liu, D. et al. Pregnancy and perinatal outcomes of women with coronavirus disease (COVID-19) pneumonia: A preliminary analysis. Am. J. Roentgenol. https://doi.org/10.2214/ajr.20.23072 (2020).

12. Albano, D. et al. Incidental findings suggestive of COVID-19 in asymptomatic patients undergoing nuclear medicine procedures in a high prevalence region. J. Nucl. Med. https://doi.org/10.2967/jnumed.120.246256 (2020).

13. Song, F. et al. Emerging coronavirus 2019-nCoV pneumonia. Radiology https://doi.org/10.1148/radiol.2020200274 (2020).

14. Pan, F. et al. Time course of lung changes on chest CT during recovery from 2019 novel coronavirus (COVID-19) pneumonia. Radiology https://doi.org/10.1148/radiol.2020200370 (2020).

15. Feng, K. et al. Analysis of CT features of 15 children with 2019 novel coronavirus infection. Zhonghua er ke za zhi = Chin. J. Pediatr. 58, E007. https://doi.org/10.3760/cma.j.issn.0578-1310.2020.0007 (2020).

16. Chan, J. F. et al. A familial cluster of pneumonia associated with the 2019 novel coronavirus indicating person-to-person transmission: A study of a family cluster. Lancet 395, 514-523. https://doi.org/10.1016/s0140-6736(20)30154-9 (2020).

17. Ye, G. et al. Clinical characteristics of severe acute respiratory syndrome coronavirus 2 reactivation. J. Infect. https://doi. org/10.1016/j.jinf.2020.03.001 (2020).

18. Qian, G. Q. et al. Epidemiologic and clinical characteristics of 91 hospitalized patients with COVID-19 in Zhejiang, China: A retrospective, multi-centre case series. QJM Monthly J. Assoc. Physicians https://doi.org/10.1093/qjmed/hcaa089 (2020).

19. Bai, H. X. et al. Performance of radiologists in differentiating COVID-19 from viral pneumonia on chest CT. Radiology https:// doi.org/10.1148/radiol.2020200823 (2020).

20. Liu, H. et al. Clinical and CT imaging features of the COVID-19 pneumonia: Focus on pregnant women and children. J. Infect. https://doi.org/10.1016/j.jinf.2020.03.007 (2020).

21. Chen, H. et al. Clinical characteristics and intrauterine vertical transmission potential of COVID-19 infection in nine pregnant women: A retrospective review of medical records. Lancet https://doi.org/10.1016/S0140-6736(20)30360-3 (2020).

22. Wu, J. et al. Clinical characteristics of imported cases of COVID-19 in Jiangsu province: A multicenter descriptive study. Clin. Infect. Dis. https://doi.org/10.1093/cid/ciaa199 (2020).

23. Xia, J., Tong, J., Liu, M., Shen, Y. \& Guo, D. Evaluation of coronavirus in tears and conjunctival secretions of patients with SARSCoV-2 infection. J. Med. Virol. https://doi.org/10.1002/jmv.25725 (2020). 
24. Xu, J. et al. Computed tomographic imaging of 3 patients with coronavirus disease 2019 pneumonia with negative virus real-time reverse-transcription polymerase chain reaction test. Clin. Infect. Dis. https://doi.org/10.1093/cid/ciaa207 (2020).

25. Lei, P. et al. Clinical and computed tomographic (CT) images characteristics in the patients with COVID-19 infection: What should radiologists need to know?. J. X-ray Sci. Technol. https://doi.org/10.3233/xst-200670 (2020).

26. Meng, H. et al. CT imaging and clinical course of asymptomatic cases with COVID-19 pneumonia at admission in Wuhan, China. J. Infect. https://doi.org/10.1016/j.jinf.2020.04.004 (2020).

27. Ji, L. N. et al. Clinical features of pediatric patients with COVID-19: A report of two family cluster cases. World J. Pediatr. https:// doi.org/10.1007/s12519-020-00356-2 (2020).

28. Deng, L. et al. Arbidol combined with LPV/r versus LPV/r alone against Corona Virus Disease 2019: A retrospective cohort study. J. Infect. https://doi.org/10.1016/j.jinf.2020.03.002 (2020).

29. Chung, M. et al. CT imaging features of 2019 novel coronavirus (2019-nCoV). Radiology https://doi.org/10.1148/radiol.20202 $00230(2020)$.

30. Feng, H., Liu, Y., Lv, M. \& Zhong, J. A case report of COVID-19 with false negative RT-PCR test: Necessity of chest CT. Jpn. J. Radiol. https://doi.org/10.1007/s11604-020-00967-9 (2020).

31. Wang, X. et al. Clinical characteristics of non-critically ill patients with novel coronavirus infection (COVID-19) in a Fangcang Hospital. Clin. Microbiol. Infect. https://doi.org/10.1016/j.cmi.2020.03.032 (2020).

32. Zhong, Q. et al. Spinal anaesthesia for patients with coronavirus disease 2019 and possible transmission rates in anaesthetists: Retrospective, single-centre, observational cohort study. Br. J. Anaesth. https://doi.org/10.1016/j.bja.2020.03.007 (2020).

33. Wang, R. et al. Epidemiological and clinical features of 125 hospitalized patients with COVID-19 in Fuyang, Anhui, China. Int. J. Infect. Dis. https://doi.org/10.1016/j.ijid.2020.03.070 (2020).

34. Zhou, S., Wang, Y., Zhu, T. \& Xia, L. CT features of coronavirus disease 2019 (COVID-19) pneumonia in 62 patients in Wuhan, China. Am. J. Roentgenol. https://doi.org/10.2214/ajr.20.22975 (2020).

35. Li, R. et al. Clinical characteristics of 225 patients with COVID-19 in a tertiary Hospital near Wuhan, China. J. Clin. Virol. 127, 104363. https://doi.org/10.1016/j.jcv.2020.104363 (2020).

36. Ai, T. et al. Correlation of chest CT and RT-PCR testing in coronavirus disease 2019 (COVID-19) in China: A report of 1014 cases. Radiology https://doi.org/10.1148/radiol.2020200642 (2020).

37. Yoon, S. H. et al. Chest radiographic and CT findings of the 2019 novel coronavirus disease (COVID-19): Analysis of nine patients treated in Korea. Korean J. Radiol. https://doi.org/10.3348/kjr.2020.0132 (2020).

38. Yang, W. et al. Clinical characteristics and imaging manifestations of the 2019 novel coronavirus disease (COVID-19): A multicenter study in Wenzhou city, Zhejiang, China. J. Infect. https://doi.org/10.1016/j.jinf.2020.02.016 (2020).

39. $\mathrm{Xu}, \mathrm{T}$. et al. Clinical features and dynamics of viral load in imported and non-imported patients with COVID-19. Int. J. Infect. Dis. https://doi.org/10.1016/j.ijid.2020.03.022 (2020).

40. Xiong, Z. et al. Construction and evaluation of a novel diagnosis process for 2019-Corona Virus Disease. Zhonghua yi xue za zhi 100, E019. https://doi.org/10.3760/cma.j.cn112137-20200228-00499 (2020).

41. Xu, X. et al. Imaging and clinical features of patients with 2019 novel coronavirus SARS-CoV-2. Eur. J. Nucl. Med. Mol. Imaging https://doi.org/10.1007/s00259-020-04735-9 (2020).

42. Xia, X. Y. et al. Epidemiological and initial clinical characteristics of patients with family aggregation of COVID-19. J. Clin. Virol. 127, 104360. https://doi.org/10.1016/j.jcv.2020.104360 (2020).

43. Wu, X. et al. Radiological findings and clinical characteristics of pregnant women with COVID-19 pneumonia. Int. J. Gynaecol. Obstet. https://doi.org/10.1002/ijgo.13165 (2020).

44. Fang, Y. et al. Sensitivity of chest CT for COVID-19: Comparison to RT-PCR. Radiology https://doi.org/10.1148/radiol.2020200432 (2020).

45. Chen, Y. et al. The presence of SARS-CoV-2 RNA in feces of COVID-19 patients. J. Med. Virol. https://doi.org/10.1002/jmv.25825 (2020)

46. Cheng, Z. et al. Clinical features and chest CT manifestations of coronavirus disease 2019 (COVID-19) in a Single-Center Study in Shanghai, China. Am. J. Roentgenol. https://doi.org/10.2214/ajr.20.22959 (2020).

47. Zhang, M. Q. et al. Clinical features of 2019 novel coronavirus pneumonia in the early stage from a fever clinic in Beijing. Zhonghua jie he he hu xi za zhi = Zhonghua jiehe he huxi zazhi = Chin. J. Tubercul. Respir. Dis. 43, E013. https://doi.org/10.3760/cma.j .issn.1001-0939.2020.0013 (2020).

48. Kimball, A. et al. Asymptomatic and presymptomatic SARS-CoV-2 infections in residents of a long-term care skilled nursing facility-King County, Washington, March 2020. MMWR Morb. Mortal. Wkly Rep. 69, 377-381. https://doi.org/10.15585/mmwr. mm6913el (2020).

49. Filiberto, D. M. et al. Radiographic predictors of therapeutic operative intervention after blunt abdominal trauma: The RAPTOR score. Eur. J. Trauma Emerg. Surg. https://doi.org/10.1007/s00068-020-01371-8 (2020).

50. Lin, C. et al. Comparison of throat swabs and sputum specimens for viral nucleic acid detection in 52 cases of novel coronavirus (SARS-Cov-2)-infected pneumonia (COVID-19). Clin. Chem. Lab. Med. https://doi.org/10.1515/cclm-2020-0187 (2020).

51. Azzi, L. et al. Saliva is a reliable tool to detect SARS-CoV-2. J. Infect. https://doi.org/10.1016/j.jinf.2020.04.005 (2020).

52. Huang, P. et al. Use of chest CT in combination with negative RT-PCR assay for the 2019 novel coronavirus but high clinical suspicion. Radiology https://doi.org/10.1148/radiol.2020200330 (2020).

53. Yuan, Y., Wang, N. \& Ou, X. Caution should be exercised for the detection of SARS-CoV-2, especially in the elderly. J. Med. Virol. https://doi.org/10.1002/jmv.25796 (2020).

54. Khodamoradi, Z., Moghadami, M. \& Lotfi, M. Co-infection of coronavirus disease 2019 and influenza A: A report from Iran. Arch. Iran. Med. 23, 239-243. https://doi.org/10.34172/aim.2020.04 (2020).

55. Arashiro, T. et al. SARS-CoV-2 and Legionella co-infection in a person returning from a Nile Cruise. J. Travel Med. https://doi. org/10.1093/jtm/taaa053 (2020).

56. Paret, M. et al. SARS-CoV-2 infection (COVID-19) in febrile infants without respiratory distress. Clin. Infect. Dis. https://doi. org/10.1093/cid/ciaa452 (2020).

57. Mao, Z. Q., Wan, R., He, L. Y., Hu, Y. C. \& Chen, W. The enlightenment from two cases of asymptomatic infection with SARSCoV-2: Is it safe after 14 days of isolation?. Int. J. Infect. Dis. https://doi.org/10.1016/j.ijid.2020.03.041 (2020).

58. Qu, J., Yang, R., Song, L. \& Kamel, I. R. Atypical lung feature on chest CT in a lung adenocarcinoma cancer patient infected with COVID-19. Ann. Oncol. https://doi.org/10.1016/j.annonc.2020.03.001 (2020).

59. Marchand-Senecal, X. et al. Diagnosis and management of first case of COVID-19 in Canada: Lessons applied from SARS. Clin. Infect. Dis. https://doi.org/10.1093/cid/ciaa227 (2020).

60. Hase, R. et al. A case of imported COVID-19 diagnosed by PCR-positive lower respiratory specimen but with PCR-negative throat swabs. Infect. Dis. https://doi.org/10.1080/23744235.2020.1744711 (2020).

61. Hirotsu, Y., Maejima, M., Nakajima, M., Mochizuki, H. \& Omata, M. Environmental cleaning is effective for the eradication of severe acute respiratory syndrome coronavirus 2 (SARS-CoV-2) in contaminated hospital rooms: A patient from the Diamond Princess cruise ship. Infect. Control Hosp. Epidemiol. https://doi.org/10.1017/ice.2020.144 (2020).

62. Kalafat, E. et al. Lung ultrasound and computed tomographic findings in pregnant woman with COVID-19. Ultrasound Obstet. Gynecol. https://doi.org/10.1002/uog.22034 (2020). 
63. Kamali Aghdam, M., Jafari, N. \& Eftekhari, K. Novel coronavirus in a 15-day-old neonate with clinical signs of sepsis, a case report. Infect. Dis. https://doi.org/10.1080/23744235.2020.1747634 (2020).

64. Karami, P. et al. Mortality of a pregnant patient diagnosed with COVID-19: A case report with clinical, radiological, and histopathological findings. Travel Med. Infect. Dis. https://doi.org/10.1016/j.tmaid.2020.101665 (2020).

65. Lv, D. F. et al. Dynamic change process of target genes by RT-PCR testing of SARS-Cov-2 during the course of a Coronavirus Disease 2019 patient. Clinica chimica acta Int. J. Clin. Chem. 506, 172-175. https://doi.org/10.1016/j.cca.2020.03.032 (2020).

66. Sivakorn, C. et al. Case report: Walking pneumonia in novel coronavirus disease (COVID-19): Mild symptoms with marked abnormalities on chest imaging. Am. J. Trop. Med. Hyg. https://doi.org/10.4269/aitmh.20-0203 (2020).

67. Marchand-Senécal, X. et al. Diagnosis and management of first case of COVID-19 in Canada: Lessons applied from SARS. Clin. Infect. Dis. https://doi.org/10.1093/cid/ciaa227 (2020).

68. Shiri, I. et al. Next-generation radiogenomics sequencing for prediction of EGFR and KRAS mutation status in NSCLC patients using multimodal imaging and machine learning algorithms. Mol. Imaging. Biol. https://doi.org/10.1007/s11307-020-01487-8 (2020).

69. Zheng, F. et al. Clinical characteristics of children with coronavirus disease 2019 in Hubei, China. Curr. Med. Sci. https://doi. org/10.1007/s11596-020-2172-6 (2020).

70. Mehdi, A. \& Riazalhosseini, Y. Epigenome aberrations: Emerging driving factors of the clear cell renal cell carcinoma. Int. J. Mol. Sci. https://doi.org/10.3390/ijms18081774 (2017).

71. Chan, J. F. et al. Improved molecular diagnosis of COVID-19 by the novel, highly sensitive and specific COVID-19-RdRp/Hel real-time reverse transcription-polymerase chain reaction assay validated in vitro and with clinical specimens. J. Clin. Microbiol. https://doi.org/10.1128/jcm.00310-20 (2020).

72. Chu, D. K. W. et al. Molecular diagnosis of a novel coronavirus (2019-nCoV) causing an outbreak of pneumonia. Clin. Chem. https ://doi.org/10.1093/clinchem/hvaa029 (2020).

73. Amrane, S. et al. Rapid viral diagnosis and ambulatory management of suspected COVID-19 cases presenting at the infectious diseases referral hospital in Marseille, France,-January 31st to March 1st, 2020: A respiratory virus snapshot. Travel Med. Infect. Dis. https://doi.org/10.1016/j.tmaid.2020.101632 (2020).

74. Stranieri, A. et al. Preliminary investigation on feline coronavirus presence in the reproductive tract of the tom cat as a potential route of viral transmission. J. Feline Med. Surg. 22, 178-185. https://doi.org/10.1177/1098612x19837114 (2020).

75. Wei, J. et al. 2019 novel coronavirus (COVID-19) pneumonia: Serial computed tomography findings. Korean J. Radiol. 21, 501-504 (2020).

76. Lin, X. et al. Novel coronavirus pneumonia outbreak in 2019: Computed tomographic findings in two cases. Korean J. Radiol. 21, 365-368 (2020).

\section{Acknowledgements}

Special thanks to Urology Research Center, Tehran University of Medical Sciences, Tehran, Iran.

\section{Author contributions}

S.M.K.A. was the principal investigator and supervisor of the project. M.S. was the epidemiologist who runs the statistical analysis of data and provides figures. S.S.T.Z. and S.Z.A. individually screened the data and make the data extraction sheet and tables of the article. F.K.H. had design the search strategy and wrote the manuscript. A.N.S. co-supervised the project and data curation. L.O.R. edited the manuscript.

\section{Competing interests}

The authors declare no competing interests.

\section{Additional information}

Supplementary Information The online version contains supplementary material available at https://doi. org/10.1038/s41598-020-80061-2.

Correspondence and requests for materials should be addressed to S.M.K.A.

Reprints and permissions information is available at www.nature.com/reprints.

Publisher's note Springer Nature remains neutral with regard to jurisdictional claims in published maps and institutional affiliations.

Open Access This article is licensed under a Creative Commons Attribution 4.0 International License, which permits use, sharing, adaptation, distribution and reproduction in any medium or format, as long as you give appropriate credit to the original author(s) and the source, provide a link to the Creative Commons licence, and indicate if changes were made. The images or other third party material in this article are included in the article's Creative Commons licence, unless indicated otherwise in a credit line to the material. If material is not included in the article's Creative Commons licence and your intended use is not permitted by statutory regulation or exceeds the permitted use, you will need to obtain permission directly from the copyright holder. To view a copy of this licence, visit http://creativecommons.org/licenses/by/4.0/.

(c) The Author(s) 2020 